\title{
EL BILDUNGSROMAN FEMENINO EN HASTA NO VERTE JESÚS MÍO DE ELENA PONIATOWSKA
}

\author{
MARÍA C. ALBIN
}

La novela Hasta no verte Jesús mío (1969) de Elena Poniatowska se basa en la vida de una mujer de pueblo, Josefina Borquez, quien adoptará el nombre de Jesusa Palancares como la protagonista de la obra. La escritora se interesó por Jesusa al escucharla hablar en un lavadero y según ella misma nos cuenta: «me pareció formidable su lenguaje y sobre todo su capacidad de indignación» ${ }^{1}$. En ese momento decidió pedirle que le narrara su vida, a lo cual Jesusa accedió a regañadientes. Poniatowska iba todos los miércoles de cuatro a seis de la tarde a casa de Jesusa con el objetivo de que ésta le narrara sus vivencias. En la elaboración de la novela, la escritora utiliza el procedimiento periodístico de la entrevista, el cual combina con el elemento de ficción que distingue a toda obra literaria. Al respecto declara:

Utilicé las anécdotas, las ideas y muchos de los modismos de Jesusa Palancares pero no podría afirmar que el relato es una transcripción directa de su vida ... podé, cosí, remendé, inventé... me limité a adivinar a la Jesusa. Acumulé aventuras, siempre me le adelanté....2.

Poniatowska confiesa que quería destacar en el texto aquellas cualidades de su personaje femenino que la distinguían de la imagen tradicional de la mujer mexicana, tales como su rebeldía, independencia y combatividad ${ }^{3}$. La protagonista de Hasta no verte Jesús mío no está delimitada ni por las características que usualmente se adjudican al género femenino, ni por el comportamiento asignado a la mujer en la sociedad ${ }^{4}$. Elena Poniatowska presenta a su personaje femenino como una mujer que a partir de la toma de conciencia de su situación personal, emprende un proceso de aprendizaje y desarrollo en busca de su autenticidad. La escritora nos describe las etapas en la vida de Jesusa que marcan su lucha por la sobrevivencia y autorrealización en una sociedad patriarcal.

La novela comienza con la declaración de Jesusa de que era la tercera vez que regresaba a la tierra y que nunca había sufrido tanto como en esta reencarnación, ya que en su existencia previa había sido reina. Jesusa intenta hallar una explicación que justifique la pobreza y los trabajos que padece en su vida presente, por lo que se interroga así misma: «¿Por qué vine de pobre esta vez si antes fui reina? Mi deuda debe ser muy pesada ya que Dios me quitó a mis padres desde chica y dejó que viniera a abonar mis culpas sola como lazarina» ${ }^{5}$.

Jesusa pierde a su madre a una edad temprana, por lo que queda junto con sus dos hermanos, Emiliano y Efrén Palancares, bajo la custodia del padre; mientras que su única hermana Petra es raptada por un peón. El padre adquiere el hábito de mudarse de un lugar a otro y de cambiar constantemente de empleo al igual que de amantes. Por lo tanto, desde los primeros años de su infancia Jesusa se acostumbra a deambular de un lado a otro, según ella misma nos cuenta:

Allá íbamos Emiliano y yo. Así tuviera yo mucho quehacer y mucho amor a la casa y todo, pues a liar el petate y vámonos a donde Dios diga. Pero a mi me daba harto contentamiento andar de única mujer con mi papá́.

El carácter andariego de Jesusa va acompañado de los celos que experimenta ante las
María C. Albin

University of Minnesota. Ha sido profesora en la Universidad de Columbia (Nueva York) y en la Universidad de Washington. Sus investigaciones han girado en torno a escritoras como Gertrudis Gómez de Avellaneda o la figura femenina en las obras satíricas de la Colonia, así como en Sor Juana Inés de la Cruz. Entre sus investigaciones encontramos ensayos dedicados a la lírica de José Lezama Lima.

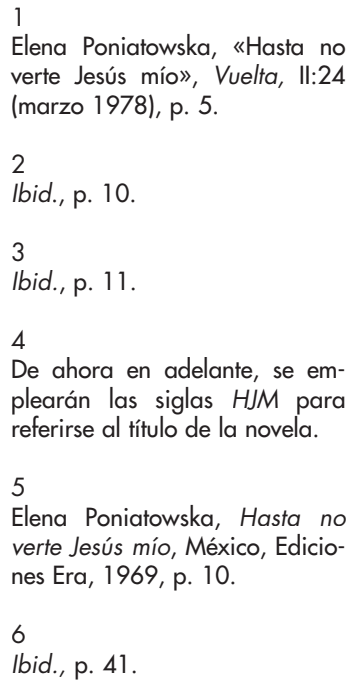
plearán las siglas HJM para referirse al título de la novela.

Elena Poniatowska, Hasta no verte Jesús mío, México, Ediciones Era, 1969, p. 10.

6 lbid., p. 41.

El Bildungsroman femenino en Hasta no verte Jesús mío de Elena Poniatowska

MARÍA C. ALBIN 
diferentes amantes que tiene el padre. La niña llega a la conclusión de que las mujeres con que su padre mantiene relaciones son por lo general abusivas, borrachas, glotonas y además despilfarran el dinero de la familia ${ }^{7}$ La única amante del padre que se convierte en su madrastra es Evarista Valencia, la hija de la rectora de una prisión. Jesusa pasa un tiempo en el presidio bajo el cuidado de Evarista, quien la enseña a trabajar, pero al mismo tiempo hace sufrir mucho a su hijastra: «Diario me pegaba mi madrastra con leños prendidos; ¡Uy, si yo sufrí bastante!»8.

Los años de la adolescencia de Jesusa transcurren dentro del marco de la Revolución Mexicana, pues la joven sigue al padre que se enlista en una corporación del ejército revolucionario. La experiencia de acompañar a las tropas revolucionarias permite que la joven adolescente alcance la independencia emocional de la figura patriarcal, pues Jesusa observa cómo la corporación llega a rechazar a su padre debido a su conducta irresponsable, ya que parecía que su único interés eran las mujeres. Además, Jesusa se queja de la doble moral que caracteriza/distingue las relaciones entre los sexos. La joven alega que las mujeres son acusadas de ser poco castas, mientras que son los varones los que siempre están dispuestos a tener una relación carnal9.

Al quedarse prácticamente huérfana, Jesusa se ve obligada a aprender cómo sobrevivir sola y a luchar por su autorrealización en una sociedad patriarcal en que una mujer pobre se halla totalmente desamparada y en desventaja debido a su clase y a su sexo. Jesusa confiesa que al verse desvalida: «Me dediqué a buscarme la vida como Dios me diera a entender. Si no, ¿cómo comía yo?»10. Jesusa decide emprender un viaje de regreso a Tehuantepec, su tierra natal, pero no lo logra y acaba casándose sin consentimiento previo con Pedro Aguilar, un oficial de la revolución mexicana. El matrimonio con el capitán carrancista le ocasiona un gran sufrimiento físico y psíquico, pues para todo la golpea. Pedro no le permitía bañarse, ni peinarse e incluso le prohibía que se cambiara de ropa para que así ningún hombre se fijara en ella. Además, la obligaba a dormir tapada con el rebozo. Al respecto, declara Jesusa: «Así que yo fui mártir. Ora no, ora ya no soy mártir. Sufro como todo el mundo pero no en comparación de lo que sufrí cuando tenía marido» ${ }^{11}$. Después de unos meses de abuso y humillación, Jesusa toma conciencia de la situación de opresión a que la tenía sometida su marido, y de inme- diato decide rebelarse. En un acto de rebelión contra Aguilar, lo confronta verbal y físicamente diciéndole que no le permitirá que le dé más palizas e incluso amenaza con balacearlo. Desde ese momento, Jesusa no acepta más la subordinación al marido y se vuelve:

... muy peleonera, muy perra. Y con los años me fue aumentando el instinto de dar antes de que me den. Se acabó aquello de agacharse a que me llovieran cachetadas y cintarazos. Supe defenderme desde el día en que me escondí la pistola en el blusón ${ }^{12}$.

Durante una escaramuza de la revolución matan a Pedro, por lo que Jesusa hereda el mando de los soldados que su marido dirigía. Sin embargo, rehusa quedarse a cargo de la tropa de su difunto esposo como quería el general Juan Espinosa y Córdova. Debido a esta decisión, el general no le paga lo que le corresponde como viuda de un combatiente revolucionario. Entonces Jesusa emprende el viaje de regreso a Tehuantepec, pero al llegar a la ciudad de México, donde le correspondía transbordar a otro tren, un cargador le roba todo el equipaje. Una vez más se queda desvalida sin un centavo, sin ropa y sin nada, según ella misma confiesa: «... me quedé sola, abandonada aquí en México, rascándome con mis uñas. Parecía una guajalota a la que se le perdieron los guajolotitos ${ }^{13}$. Ante esta situación de desamparo, Jesusa se ve obligada a iniciar una nueva vida en la gran ciudad, donde Raquelita e Isabel Chamorro le muestran la importancia y la utilidad del dinero y también le enseñan cuáles eran los días de la semana y los meses del año. Ella misma reconoce su ignorancia: «Yo era muy cegada, muy cegada» ${ }^{14}$.

Jesusa comienza a ganarse la vida como criada en casa de una señora española, doña Pepita, donde se hace cargo de todo el quehacer doméstico: lavar, planchar y limpiar. Después de desempeñarse como sirvienta en casa de otra señora, decide abandonar el oficio de criada doméstica para trabajar como aprendiz en una fábrica de cajas de calzado. A partir de ese momento, según nos dice ella misma su vida transcurrió entre

...fábricas y fábricas, y talleres y changarros y piqueras y pulquerias y cantinas y salones de baile y más fábricas y talleres y lavaderos y señoras fregonas y tortillas duras y daleque dale con la bebedera del pulque, tequila ... Y amigos y amigas que no servían para nada, y perros que me dejaban sola por andar siguiendo a sus perras. $Y$ hombres peores que perros 
del mal y policías ladrones y pelados abusivos. Y yo siempre sola, y el muchacho que recogí de chiquito y que se fue y me dejó más sola ... cada vez más desmadejada en esta chingadera de vida ${ }^{15}$.

HJM puede ser considerada un Bildungsroman femenino que se desvía del modelo masculino de este género literario. El Bildungsroman es el concepto empleado para definir aquellas narraciones cuyo tema es la representación literaria de las experiencias de un personaje que se somete a un proceso de aprendizaje y maduración que tiene como objetivo la integración del individuo a su contexto social. Según la definición clásica de Bildungsroman, término acuñado por Wilhelm Dilthey, este tipo de novela se distingue por presentar el desarrollo metódico en la vida de un personaje como una serie de etapas, las cuales se encuentran vinculadas entre sí, ya que la anterior sienta los cimientos de la próxima fase. De ahí que las disonancias y conflictos que experimenta el individuo a lo largo de su vida, sean necesarios en el transcurso de su desarrollo hacia la madurez y armonía consigo mismo. Por lo tanto, estos relatos de formación ponen énfasis en el proceso de crecimiento del protagonista que puede abarcar el desarrollo emotivo e intelectual del sujeto en cuestión ${ }^{16}$.

La interacción individuo-sociedad rige estas novelas de aprendizaje, por lo que el relato se estructura en base a las relaciones que se van forjando entre el protagonista y el medio social. El personaje principal no controla su destino, sino que más bien reacciona frente a sus circunstancias. El contexto socio-político, las relaciones que va estableciendo con otros individuos, los hábitos y códigos de conducta de su clase social y de su género sexual, constituyen el trasfondo sobre el cual se entreteje la acción en estos textos en los que se narra cómo se va configurando la identidad del protagonista.

En su estudio sobre los relatos de formación de la protagonista femenina en la literatura hispanoamericana, María Inés Lagos ofrece una caracterización más amplia del género. La crítica alega que en la introducción al libro The Voyage In, las editoras nos brindan una definición más flexible del Bildungsroman que se puede aplicar a las novelas de las escritoras. Por lo general, en el relato de formación femenino se subvierten los valores que se subrayan en su versión masculina, y se da una marcada discrepancia entre los deseos de la protagonista y el modelo de conduc- ta que le impone la sociedad. De ahí que el Bildungsroman femenino recurra a diversas estrategias narrativas con el objetivo de lograr una inversión o reverso irónico de las normas de comportamiento que se establecen para la mujer a partir de un sistema de códigos genéricos rígido ${ }^{17}$.

Lagos aclara que además de considerar las novelas de formación de un personaje femenino una desviación del modelo masculino de Bildungsroman, algunas críticas proponen que se establezcan distinciones en la terminología con que se designan estos textos. Por ejemplo, las editoras de The Voyage In sugieren que se llamen a estos relatos de formación «ficciones de desarrollo femenino» (fictions of female development); mientras que Rita Felski opina que es necesario llevar a cabo una clasificación de este corpus heterogéneo de escritos. La crítica denomina «narrativas de auto-descubrimiento femenino» (narratives of female self-discovery) a aquellos relatos contemporáneos que se centran en la mujer y que logran superar la dicotomía matrimonio-muerte. Además, establece una diferencia entre los textos en que la protagonista llega a la conclusión de que no es posible alcanzar un desarrollo pleno en la sociedad patriarcal, a los cuales clasifica como "Bildungsroman femenino» (feminine Bildungsroman), y las novelas del despertar o auto-descubrimiento (novel of awakening) en que el personaje principal, una mujer, percibe su identidad femenina como una fuerza que se opone a los valores socio-culturales vigentes ${ }^{18}$.

Por otro lado, Lagos señala que las editoras de la colección de ensayos sobre las novelas de formación femenina, Abel, Hirsch y Langlad, en su introducción a The Voyage In, revisan y amplian la definición del género al incluir variantes que no se tomaban en cuenta en el concepto tradicional. Según las editoras, entre las obras que integran las versiones femeninas del Bildungsroman se encuentran textos que presentan la posibilidad de un yo coherente, pero que no llega a asumir la postura de un sujeto autónomo; relatos que muestran una confianza total en el proceso de aprendizaje y crecimiento del personaje femenino; narraciones que se dedican a describir un lapso de tiempo en el que ocurre el desarrollo de la protagonista; y novelas en las que se enfatiza el contexto social. Las editoras llegan a la conclusión de que esta variedad de
15 lbid., pp. 147-148

16

María Inés Lagos, En tono mayo, Santiago de Chile, Ed. Cuarto Propio, 1996, pp. 30-32.

17 Ibid., pp. 34-36.

18

Rita Felski, Beyond Feminist Aesthetics: Feminist Literature and Social Change, Cambridge, Harvard University Press, 1989, pp. 122-153.

El Bildungsroman femenino en Hasta no verte Jesús mío de Elena Poniatowska

MARÍA C. ALBIN 


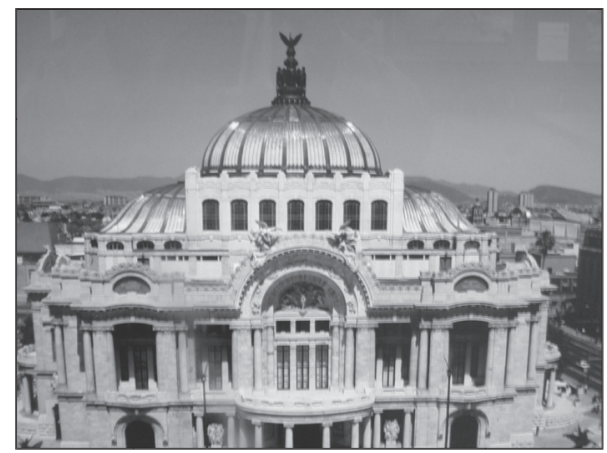

Palacio de Bellas Artes.

19

Lagos, op. cit., pp. 45-46.

20

Poniatowska, HJM, pp. 153,

295. obras constituye una prueba de que en el caso de las mujeres, las alternativas de desarrollo y acción resultan más limitadas que las de los hombres. Además, alegan que la ficción femenina se distingue de la masculina en que el proceso de desarrollo de la protagonista suele ser menos directo y más conflictivo, y advierten que por lo general la mujer aspira a alcanzar su autonomía e independencia al mismo tiempo que quiere mantener relaciones íntimas. Por último, las editoras concluyen que los relatos femeninos se diferencian de los masculinos con respecto al carácter del proceso de desarrollo, pues en el caso de la mujer éste no es gradual, sino que se realiza a través de momentos epifánicos y no se circunscribe a la etapa de la adolescencia ${ }^{19}$.

La novela de Poniatowska se aparta del modelo masculino del Bildungsroman, postura que asumen algunas escritoras que articulan en sus obras el tema del crecimiento y desarrollo de una protagonista femenina. $H J M$ como novela de formación de un personaje femenino, es un relato que al abordar el tema de la configuración de la identidad de la mujer desestabiliza el modelo tradicional de feminidad y de ese modo permite la elaboración de nuevos discursos sobre la diferencia del género sexual. Pero el relato de la escritora no sólo difiere del modelo establecido porque trata del desarrollo de un personaje femenino, sino también porque muestra la historia de un período político y cultural con respecto a las aspiraciones de las mujeres y las limitaciones que le impone la sociedad en el proceso de formación y crecimiento debido a la existencia y propagación de unas ideas fijas sobre las categorías sexuales y las diferencias genéricas.

La trama de la novela de Poniatowska muestra las tensiones que configuran el proceso de aprendizaje y desarrollo de su personaje femenino, a la vez que encubre una postura de rebelión por parte de Jesusa. En HJM el conflicto que la protagonista enfrenta en el proceso de crecimiento e integración a su medio social se ve complicado por el contexto socio-político que adquiere importancia en el relato. La acción de la novela se sitúa en una época de disturbios y de cambios sociales y políticos que añaden complejidad al proceso de la constitución de la identidad del personaje femenino.
La protagonista confronta un medio social que espera que la mujer se defina a sí misma en base al amor, al matrimonio y a la maternidad. La dualidad que experimenta Jesusa se manifiesta en la contradicción que percibe entre la libertad que desea y las limitaciones que le impone el medio externo. La heroína de Poniatowska entra en conflicto con el modelo de feminidad establecido, pues rechaza la maternidad biológica y después de quedar viuda, decide no volver a contraer matrimonio nunca más. Además, Jesusa denuncia el doble criterio para juzgar la moralidad de hombres y mujeres. Esta disparidad entre las convenciones y normas de conducta que le impone la sociedad y su búsqueda de autonomía y autodeterminación, propicia el despertar de la protagonista quien toma conciencia del dilema que representa su interacción con el ámbito social.

Por lo general, los personajes femeninos eran representados en las novelas como individuos pasivos anulando la posibilidad de que surgiera un sujeto femenino autónomo y dinámico. Antes de que el movimiento feminista comenzara a cuestionar la imagen tradicional de la mujer, las protagonistas que se encontraban avanzadas en el proceso de crecimiento y desarrollo acababan por ser derrotadas al final del relato: unas morían o se suicidaban, mientras que otras optaban por la locura o alguna forma de seclusión del mundo exterior.

Por el contrario, Elena Poniatowska revisa este modelo pasivo de lo femenino en $H J M$, al adjudicar a su protagonista Jesusa Palancares, un carácter dinámico que le permite desarrollar el «arte de vivir» y de «sobrevivir». Jesusa posee un temperamento independiente y rebelde, y además valora profundamente el ser libre que en su caso está intimamente vinculado a la soledad. Ella misma declara: «Por eso yo soy sola, porque no me gusta que me gobierne nadie» y más adelante reitera «Soy muy feliz aquí solita. Me muerdo yo solita y me rasguño, me caigo y me levanto yo solita. Soy muy feliz. Nunca me ha gustado vivir acompañada» ${ }^{20}$.

Desde niña, Jesusa se acostumbró a ser andariega. Primero, siguió a su padre de un lado a otro y luego acompañó a su marido durante la lucha armada revolucionaria. Una vez radicada en el D.F., se muda constantemente dentro de la ciudad, pues como ella misma nos explica:

Como a nadie le tengo que rendir cuentas, nomás me salgo y adiós. Me voy por allí sin rumbo o 
por un camino que yo sola discurro. Así soy, hija de la mala vida, acostumbrada a ir de un lado a otro y a poner en cualquier parte los palos de mi sombrajo ${ }^{21}$.

Jesusa se desvía del modelo de comportamiento femenino, pues declara no haber nacido para cocinar y, en cierto modo, cuestiona la maternidad como destino de la mujer. Ignacia, la esposa de su hermano Efrén, trata de enseñarle cómo hacer tortillas. $\mathrm{Al}$ respecto, nos cuenta Jesusa: «Decía que a manazos tenía que enseñarme, pero pues no nací para echar tortillas y nunca he sabido tortear» ${ }^{22}$. Por otro lado, a pesar de que cría a Perico, el hijo de una amiga difunta, rechaza la maternidad, pues alega que «lavar es pesado, pero según yo, es más pesado cuidar niños. A mi los niños nunca me han gustado. Son muy latosos y malas gentes» ${ }^{23}$. Por lo tanto, el personaje de Jesusa se aparta de la imagen convencional que se tiene de la mujer mexicana que pertenece a la clase humilde.

Después de quedar viuda de Pedro, Jesusa decide nunca más volver a casarse y permanecer soltera por el resto de su vida, ya que prefiere estar sola a tener que rendirle cuentas a un hombre. Dos extranjeros le proponen matrimonio, un banquero y un capitán que conoce en Marfa, TX, pero a ambos rechaza. La protagonista de $H J M$ confronta un medio social que espera que la mujer se defina a sí misma en base al amor, al matrimonio y a la maternidad, lo cual propicia el despertar de Jesusa, quien se percata de que la mejor opción para ella es permanecer sola si aspira a alcanzar su autonomía e independencia. En el siguiente pasaje, Jesusa asume de forma explícita la postura de un sujeto autónomo que prefiere dejar a un lado las relaciones íntimas con el sexo opuesto:

Dicen que el buey solo bien se lame, ¿por qué la vaca no? ¿Cómo podía adivinar si me iba a ir bien, casada con un extranjero? Para ser malo el hombre, lo mismo es extranjero que mexicano. Todos pegan igual ... Mejor pasar necesidades que aguantar marido. A mi los hombres no me hacen falta ni me gustan, más bien me estorban aunque no están cerca de mi, ¡Ojalá y no nacieran! ${ }^{24}$.

Más adelante, denuncia el carácter de los hombres y reitera su propuesta de emancipación femenina: «Los hombres son siempre abusivos. Como si eso fuera ser hombre... $\mathrm{Y}$ se equivocan porque no todas somos sus yeguas mansas» ${ }^{25}$.
El personaje femenino de Jesusa no sólo rompe con el código de conducta asignado a las mujeres, sino que además rechaza y se rebela en contra del dominio masculino sobre su sexo. Jesusa valora demasiado su independencia y libertad como para dejarse gobernar por un hombre. Ella se siente capaz de realizar todo lo que los varones hacen y la única relación que logra establecer con ellos es la de ser su amiga o compañera de parrandas: «A mi al cabo ni me gustan los pelados. A mi, sáquenme a bailar, llévenme a tomar y jalo parejo, invítenme a dar la vuelta por todo México; denme harto que comer y tomar, pero eso sí a mí no me digan que les pague con lo que Dios me dio. Eso si que no... Soy de todos por las buenas, pero de nadie por las malas» ${ }^{26}$.

Desde una edad temprana, Jesusa muestra una predilección por las actividades que llevan a cabo los muchachos para divertirse, tales como: correr gallo, cantar con la guitarra, jugar al trompo o a las canicas y matar lagartijas a pedrazos. La propia Jesusa confiesa: «Yo era muy hombrada y siempre me gustó jugar a la guerra, a las pedradas... a la lucha, a las patadas, a puras cosas de hombres... ${ }^{27}$. La inclinación de Jesusa por imitar el comportamiento masculino se manifiesta una vez más cuando decide reclutarse como voluntaria en la guerra de los cristeros, pues como ella misma nos dice: "como que no, si se trataba de echar balazos, vamos a darle. Me fui y cualquier día me vuelvo a ir donde se arme la bola, pero que haya balazos, muchos balazos...» ${ }^{28}$.

Elena Poniatowska concluye que detrás de esa imagen de mujer recia y osada, Jesusa Palancares esconde una gran humanidad que expresa en la ternura y compasión que siente por los demás. Por ejemplo, recoge a Rufino y Perico, dos niños desamparados. Al primero lo encuentra vagando por Ciudad Valles, por lo que lo alberga, lo viste, lo calza y le da de comer, e incluso le enseña un oficio. Pero al cabo de dos años de vivir bajo su techo, Rufino huye de la casa de Jesusa llevando consigo los cuchillos de la matanza de cochinos y la báscula. A pesar de haber recibido un mal pago por su caridad y bondad, se hace cargo de Perico, el hijo de su vecina Felícitas, quien muere dejando huérfanos a varios niños. Los hijos de Felicitas viven tres años con Jesusa porque el padre, José del Carmen Vidales,
21

Ibid., p. 238

22

Ibid., p. 280

23

Id.

24

Ibid., p. 173

25

Ibid., pp. 177-178.

26

Ibid., p. 153.

27

Ibid., p. 70.

28

Ibid., p. 206.
El Bildungsroman femenino en Hasta no verte Jesús mío de Elena Poniatowska

MARÍA C. ALBIN 


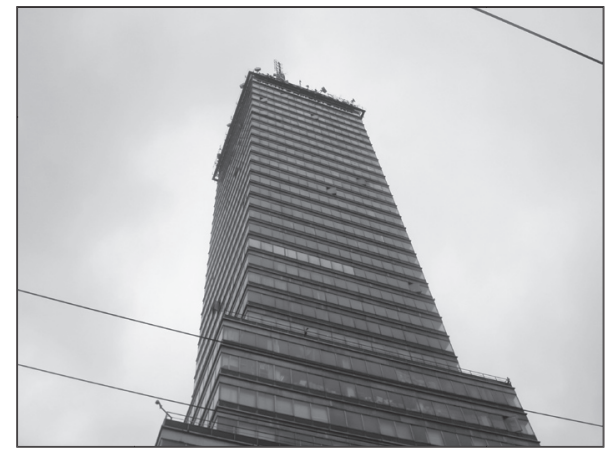

Torre Latinoamericana.

29

lbid., p. 306.

30

lbid., p. 312

31

lbid., p. 186

32

Ibid., p. 305

33

lbid., p. 186 los tenía abandonados y no se ocupaba de ellos. Al respecto, Jesusa concluye: «Los hombres que después ni se ocupan de los hijos, sí se ocupan de andar contando por las esquinas que ya les nació un hijo. Y con ese pretexto agarran la borrache$\mathrm{ra}^{29}$.

Jesusa llega a criar a Perico e intenta que el joven asista a la escuela para que llegue a convertirse en un hombre de bien. Sin embargo, Rogaciana, la tía del muchacho le aconseja que ya que sabía leer y escribir debía dejar a Jesusa e irse a trabajar. Perico sigue el consejo que le da su tía y abandona a Jesusa, quien nos cuenta:

Perico estuvo conmigo mientras me necesitó; pero apenas pudo agarró su camino. Yo nunca he deseado hijos, ¿para qué? Si con trabajos me mantengo yo... A Perico lo crié porque no tenía madre. Eso es recoger a un inocente. Pero no lo crié para que me durara toda la vida ... al fin que todo está predestinado por la mano omnipotente $e^{30}$.

Después de quince años, Perico regresa a casa de Jesusa quien ya está vieja. Sin embargo, recibe una vez más alojamiento y comida a pesar de que cree que el retorno del joven se debía a que quería heredar las pocas pertenencias de la anciana.

Jesusa Palancares representa una nueva versión del personaje femenino en la literatura, una heroína que reúne características atribuídas tanto al género masculino como al femenino. Jesusa posee el dinamismo, la independencia, la combatividad y la valentía que generalmente se asocian al sexo masculino. Ella misma confiesa: «El coraje, ese me sostenía. Toda mi vida he sido mal geniuda, corajuda», y luego añade: «Para mi no existe el miedo. ¿Miedo a qué? Solamente a Dios» ${ }^{31}$. Por otro lado, a pesar de declararse «madre seca,» exhibe las características de ternura e instinto de protección que se le adjudican al género femenino por su capacidad biológica de la maternidad ${ }^{32}$. Jesusa no reniega el ser mujer, pero está plenamente consciente de que el ser hombre le otorgaría un mayor grado de libertad en la sociedad. De ahí que confiese abiertamente:

El Bildungsroman femenino en Hasta no verte Jesús mío de Elena Poniatowska

MARÍA C. ALBIN ...pero de gustarme, me gusta más ser hombre que mujer. Para todas las mujeres sería mejor ser hombre, seguro, porque es más divertido, es uno más libre y nadie se burla de uno... ¡Mil veces mejor ser hombre que mujer! ¡Bendita la mujer que quiere ser hombre! $!^{33}$.

Por lo tanto, Jesusa representa una heroína cuyo carácter y conducta no se hallan delimitadas por su género sexual, ya que según hemos visto exhibe características tradicionalmente asignadas a cada uno de los sexos.

La relación entre la mujer y el lenguaje ha sido estudiada por las feministas francesas, quienes han desarrollado el concepto de l'écriture féminine. El término alude a una práctica de la escritura en lo femenino que socava las convenciones linguísticas, sintácticas y metafísicas de la narrativa occidental. El concepto de l'écriture féminine ha sido empleado por Hélène Cixous para referirse a un modo de escribir que afirma la diferencia y explora los poderes de la mujer. Para Cixous, la escritura femenina implica la inscripción en el lenguaje del cuerpo femenino en toda su diferencia mediante la liberación del inconsciente reprimido de la mujer. La crítica francesa llega a la conclusión en dos de sus ensayos, «Le rire de la Méduse» (1975) y «La Venue à l'écriture», que la economía pulsional o libidinal femenina se traduce en una escritura que no se puede definir o teorizar. En sus escritos, Cixous denuncia las restricciones que la cultura dominante y masculina ha impuesto a la mujer impidiéndole sentir que tiene derecho a escribir, al mismo tiempo que hace un llamado a las mujeres a acercarse a su cuerpo y al placer de la escritura.

Este tipo de escritura no se limita exclusivamente a las mujeres, sino que se trata más bien de un estilo de escritura vanguardista. Para las críticas francesas, l'écriture féminine está vinculada a los ritmos biológicos del cuerpo femenino y al goce sexual (jouissance), y es en sí misma un modelo de escritura subversivo y revolucionario. Las críticas sostienen que las escritoras deben de intentar representar en sus textos todo aquello que se encuentra silenciado en la cultura. Esta es precisamente la estrategia que adopta Poniatowska en su novela al dejar hablar aquello que permanecía silenciado, pues le otorga voz a una mujer humilde que nos relata su propia historia que está vinculada a la de su pais.

Poniatowska cree en ese poder del silencio que al romperse por medio de la literatura, llega a ser escuchado alcanzando así su mayor vigor. De ahí que titule uno de sus libros: Fuerte es el silencio (1980). Pero este silencio al que estaba sometida su protagonista feme- 
nina hasta que la escritora la deja hablar en su novela, se caracteriza también por su fuerza subversiva y de transgresión. Hélène Cixous, la más conocida teórica de l'écriture féminine, así lo confirma en su manifiesto «Le rire de la Medusa» cuando declara que la escritura representa la misma posibilidad de cambio, esto es, el espacio que fomenta el pensamiento subversivo que hace posible la transformación de las estructuras culturales y sociales ${ }^{34}$. Más adelante, la crítica añade que un texto femenino no puede ser más que subversivo porque en sí mismo es volcánico ${ }^{35}$.

Por lo tanto, el proyecto de una escritura femenina definido por Cixous con su énfasis en el cuerpo de la mujer y en la erupción del goce femenino, al ser un modo de escribir que cuestiona los aparatos conceptuales heredados puede instaurar una revolución en el discurso. La crítica francesa afirma que son las mujeres quienes se encuentran más capacitadas para llevar a cabo dicho proyecto, el cual traería consigo cambios en el inconsciente, en las relaciones entre los sexos, y en la vida social y política.

La voz de Jesusa en HJM resulta subversiva por diversas razones. Primero, porque al narrar sus experiencias en el proceso de desarrollo se desvía de las normas de conducta que la sociedad le impone a su sexo. Segundo, porque el lenguaje que Jesusa emplea para relatar los acontecimientos que marcan su vida, lejos de ser sumiso y sentimental, se distingue por su carácter contestatario. Es decir, al asumir una postura de un sujeto autónomo pero consciente de haber sido marginada en la sociedad, desestabiliza el modelo tradicional de feminidad y de ese modo, en los intersticios del discurso subyace y se inscribe la posibilidad de un lenguaje que denuncia el orden vigente, en particular en lo que se refiere al papel asignado a la mujer en la sociedad. Por lo tanto, el lenguaje que emplea Jesusa establece un discurso de crítica social.

El contexto socio-político adquiere una gran importancia en el relato de su vida, pues le toca vivir una época de disturbios políticos y de cambios e inestabilidad en la sociedad mexicana. La crisis política agudiza la conciencia de la protagonista, quien observa con cautela esta sociedad en transformación y emite sus comentarios al respecto. Jesusa expresa su descontento con la revolución, pues alega que no ha logrado implementar las reformas necesarias en la sociedad, e incluso llega a la conclusión de que la situación de los pobres ha empeorado porque siguen más muertos de hambre que antes. Al referirse a los revolucionarios declara: «A mí esos revolucionarios me caen como patada en los... bueno como si tuviera güevos. Son puros bandidos, ladrones... ¡Puro revolucionario cabrón!» ${ }^{36}$. A pesar de ser una mujer de pueblo carente de educación formal, se siente capacitada para emitir un juicio sobre la revolución a la que describe como una maniobra de poder. Al respecto nos dice: «Así fue la revolución, que ahora soy de éstos, pero mañana seré de los otros, a chaquetazo limpio, el caso es estar con el más fuerte, el que tiene más parque.... ${ }^{37}$.

Jesusa cuestiona la versión que elabora la historia oficial en torno a una figura destacada del proceso revolucionario: Francisco Villa, por quien siente un gran desprecio. En el pasaje a continuación, ofrece una versión femenina que contradice la que postula la historia oficial al presentar a Villa no como un héroe de la revolución mexicana, sino como un cobarde bandido que acostumbraba a despojar a los demás de sus bienes y a abusar de las mujeres:

No peleaba como los hombres, sino que se valía de dinamitar las vías cuando iban pasando los trenes... Si el tren era de pasajeros también lo volaba y se apoderaba del dinero y de las mujeres que estaban de buena edad... Ahora es cuando le resulta dizque una 'señora esposa' y dizque hijos y que hijas. ¡Mentira! Esas son puras vanaglorias que quieren achacarle para hacerlo pasar por lo que nunca fue $e^{38}$.

En el transcurso de su vida, Jesusa llega a conocer personalmente a dos presidentes de la república: Venustiano Carranza y Lázaro Cárdenas, sobre los cuales también nos da su opinión. Conoce a Carranza durante una audiencia que tiene con el presidente en la que le solicita que le pague la pensión que le corresponde como viuda de un soldado revolucionario. El presidente se niega a darle el dinero que le pertenece alegando que no le hacía falta porque ella era una mujer joven que podía trabajar para mantenerse a sí misma. Jesusa confiesa que la injusticia cometida por el presidente le «dio harto coraje. Sentí que la ruina me subía y hasta se me volvió sudor... Pero Carranza se quedó con mi dinero, maldecido» ${ }^{39}$.

Por otro lado, nos cuenta que conoció a Lázaro Cárdenas como soldado raso antes de que llegara a la presidencia «y no de fanfarrón con todo su Estado Mayor, con su gente, dando órdenes de secretito a todos sus achichincles...» ${ }^{40}$. Jesusa se queja de que una vez
34

Hélène Cixous, "The Laugh of the Medusa», en Elaine Marks and Isabelle de Courtivron (eds.), New French Feminisms: An Anthology, New York, Schocken, 1981, p. 249.

35

Ibid., p. 258

36

Poniatowska, HJM, p. 137.

37

lbid., p. 71.

38

lbid., p. 95-96

39

Ibid., p. 136.

40

Ibid., p. 265.
El Bildungsroman femenino en Hasta no verte Jesús mío de Elena Poniatowska

MARÍA C. ALBIN 
se encontró con Cárdenas, pero que éste no la reconoció «porque los jefes no se pueden fijar en las gentes y más cuando son pobres como yo» ${ }^{41}$.

Según hemos visto, Poniatowska en su novela hace partícipe del proceso histórico mexicano a su personaje femenino, una mujer de pueblo que al romper su mutismo nos brinda una versión de la historia distinta de la versión oficial. De ese modo, la escritora no sólo presenta a Jesusa como agente de la historia, sino también como un testigo que observa y narra los acontecimientos históricos ofreciendo su propia interpretación de los mismos. A modo de conclusión, se podría decir que, en la novela de Elena Poniatowska, Jesusa también llega a adquirir una filosofía de la vida en el proceso de su aprendizaje y gradual conocimiento de sí misma y de la naturaleza del mundo.

\section{BIBLIOGRAFÍA}

Abel, Elizabeth, Marianne Hirsch, y Elizabeth Langland (eds.), The Voyage In: Fictions of Female Development, Hanover, N.H., University Press of New England, 1983.

Cixous, Hélène, «The Laugh of the Medusa», en New French Feminisms: An Anthology, ed. Elaine Marks and Isabelle de Courtivron, New York, Shocken, 1981, pp. 245-64.

Felski, Rita, Beyond Feminist Aesthetics: Feminist Literature and Social Change, Cambridge, Harvard University Press, 1989.

Lagos, María Inés, En tono mayo, Santiago de Chile, Editorial Cuarto Propio, 1996.

Poniatowska, Elena, Hasta no verte Jesús mío, México, Ediciones Era, 1969.

- «Hasta no verte, Jesús mío», Vuelta II; 24, (marzo 1978), pp. 5-11.
El Bildungsroman femenino en Hasta no verte Jesús mío de Elena Poniatowska

MARÍA C. ALBIN 